\title{
Хасан Ахед
}

\section{Национальные арабские инструменты и их применение в музыкальной педагогике}

\begin{abstract}
В последнее время во многих странах мира исследователи, ученые, преподаватели-практики уделяют большое внимание теоретическим аспектам музыкального образования, которое рассматривается как важное условие комплексного, глубокого, всестороннего полноценного воспитания и образование молодого поколения. В арабском мире всегда проявляли большой интерес к музыкальному искусству и обращались к ней как индустрию с почтением и уважением. Халифы, принцы, философы и ученые изучали музыку и ценили ее. В настоящее время занятие музыкой или уроки музыки в школьном образовании являются важнейшей составляющей в развитии личности детей. Статья посвящена рассмотрению программ, применяемых на уроках музыки в школьном образовании в Сирийской Арабской Республике (САР). Особое внимание уделяется методам, основанным на музицировании с использованием национальных музыкальных инструментов, таких как: уд, канун, най. Анализируются истоки возникновения национальных музыкальных инструментов и способов их сохранения и развития в настоящее время.
\end{abstract}

Ключевые слова: музыкальная педагогика, Сирийская Арабская Республика, школьная педагогика, музицирование, национальные музыкальные инструменты, уд, канун, най

\section{Hasan Ahed}

\section{National Arab instruments and their application in music education}

Recently, in many countries of the world, researchers, scientists, and practicing teachers have paid great attention to the theoretical aspects of music education, which is considered an important condition for a comprehensive, deep, comprehensive full-fledged upbringing and education of the young generation. The Arab world has always shown a great interest in the art of music and treated it as an industry with reverence and respect. Caliphs, princes, philosophers, and scholars have studied and appreciated music. Currently, music lessons or music lessons in school education are the most important component in the development of the personality of children. The article is devoted to the consideration of the programs used at music classes in school education in the SAR. Particular attention is paid to methods based on playing music using national musical instruments such as oud, kanun, nai. Also, the article deals with the origins of the national musical instruments and the ways of their preservation and development at the present time.

Keywords: musical pedagogy, Syrian Arab Republic, school education, playing music, national musical instruments, oud, kanun, nai

Dol 10.30725/2619-0303-2021-1-151-155

В последнее время во многих странах мира исследователи, ученые, преподаватели-практики уделяют большое внимание теоретическим аспектам музыкального образования, которое рассматривается как важное условие комплексного, глубокого, всестороннего полноценного воспитания и образование молодого поколения. Музыкальное образование, например, в Сирии рассматривается как необходимая дисциплина, которая не только связана с развитием навыков профессионального музыкального образования, но, также нацелена на воспитание гармоничного человека, широко образованного, способного оказывать влияние на принятие политических решений, человека-созидателя. По мнению профессиональных исследователей, музыкальное образование может оказывать влияние на определенные достижения страны в новейшей истории.

Музыкальное искусство известно людям с незапамятных времен и стало важной частью требований индивидуальной и коллективной жизни. Музыка является пищей и целителем для души, вдохновляющим искусством, успокаивающим нервы и развивающим художественное мышление.

В арабском мире всегда проявляли большой интерес к музыкальному искусству и обращались к нему с почтением и уважением. Халифы, принцы, философы и ученые изучали музыку и ценили ее.

В настоящее время занятие музыкой или уроки музыки в школьном образовании являются важнейшей составляющей в развитии личности детей. Музицирование на национальных 
музыкальных инструментах: уд, канун, най предпочтительно для музыкального развития и воспитания детей.

Арабские музыканты и мастера добились больших успехов в этой области, а также в производстве музыкальных инструментов и их технологий. Некоторые из них изобрели уд, который является центральным арабским инструментом, особенно после того, как блестящий музыкант Зирьяб внес в него значительные улучшения, такие как добавление пятой струны к своим четырем струнам. Именно он изобрел плектор из орлиных перьев [1]. Великие музыканты Багдада в эпоху Аббасидов (1250-750 гг. н. э.), такие как Исхак и Ибрагим аль-Мавсили, преуспели в игре на этих инструментах, и самым ярким из них был Зирьяб1, который переехал из Багдада в Андалусию, где он был принят при дворе халифа Абдул Рахмана бин Аль-Хакама.

Вдохновленный андалузской средой и ее роскошью, Зирьяб создавал произведения в системе «мувашахат». Он основал свою первую школу в Андалусии.

Как мы уже упоминали, Сирия стала родиной многих музыкальных инструментов, которые до сих пор представляют культурный интерес и используются в практической жизни. Рассмотрим наиболее популярные национальные арабские инструменты, которые применяются сегодня в сирийской музыкальной педагогике.

Одним из самых популярных музыкальных инструментов в арабском мире является уд, о котором мы уже упоминали. Можно утверждать, что более половины учителей музыки в сирийских школах используют уд на уроках музыки.

Уд был известен в древних цивилизациях, первыми из которых были Вавилон и Ассирия в аккадскую эпоху. Эту эпоху исследователи изучили до 2500 г. до н. э. Исследования, опубликованные о первой родине и истории уда, были очень многочисленными, и некоторые из них упоминали, что уд является шумерским, другие указывали, что он был турецким, а другие приписывали его древним египтянам. Иракский музыкальный исследователь доктор Субхи Анвар Рашид 2 считает, что европейские исследователи уделили много внимания истории и происхож-

${ }^{1}$ Абу аль-Хасан ибин Нафи (789-857) был уникальной личностью своего времени - музыкантом, певцом, поэтом, химиком, астрономом. Изобрел мувашах и добавил струны уда, сделав их пятью. Свое прозвище Зирьяб, название маленькой черной птицы, он получил изза своего смуглого цвета кожи.

2 Субхи Анвар Рашид, иракский музыкальный исследователь, написал одну из важных книг, «Историю арабской музыки» и его последнюю книгу об уде. дению уда, по словам Рашида, это связано с тем, что Хорнбостель и Курт Закс ${ }^{3}$, которые работали над научной классификацией музыкальных инструментов, согласились, что большинство музыкальных инструментов попадают под удовый инструмент, независимо от того, играть на них плектером или смычком, как на скрипке. Рашид также считает, что уд впервые появился в Месопотамии, в аккадскую эпоху 2300-2170 гг. до н. э., а уд был известен в Леванте в восемнадцатом веке до нашей эры, оттуда он попал в Египет в шестнадцатом веке до нашей эры. Уд был первым струнным инструментом, известным последующим цивилизациям, и этот инструмент продолжал перемещаться в соответствии с различными размерами, грифами и струнами.

Позже, пройдя долгий путь, уд эволюционировал и перешел к фараонам и персам, затем к туркам, и по сей день уд находится в состоянии постоянного развития с точки зрения формы, технологий и акустических пространств [2].

Уд, состоящий из трех основных частей, корпуса, короткого безладового грифа и головки, был одним из первых струнных инструментов и продолжает свое существование в различных модификациях. Пройдя долгий путь своего развития, уд присутствовал в культурах египтян, персов и тюрков, находясь в состоянии постоянного развития с точки зрения формы, технологий и акустических пространств [3].

Корпус уда, напоминающий по форме грушу, делают из таких пород дерева, как орех, груша или сандал. Струны - из натуральной (шелковой) или искусственной (капроновой) нити, или же из кишок барана. Их настраивают при помощи прикрепленных к головке уда колкам. Количество струн разнится в зависимости от региона - в Средней Азии их пять, а арабских странах - от двух до семи. Классическим же вариантом считается четырехструнный уд с квартого-секундовой настройкой. Для звукоизвлечения используется плектр. Используемый как сольно, так и ансамблево, уд во время исполнения расположен горизонтально на правом колене и прижат к груди, поддерживаемый левой рукой за шейку. В XX в. исполнительство на уде вышло на новый уровень своего развития, в особенности благодаря мастерству и таланту таких выдающихся музыкантов, как сирийско-египетский исполнитель на уде и композитор Фарид аль-Атраш (1915-1974), иракский исполнитель на уде, один из самых известных средневосточ-

3 Принятая в мире система классификации музыкальных инструментов. Австрийский музыковед Эрих Мориц фон Хорнбостель (1877-1935) и немецкий музыковед Курт Закс (1881-1959) систематизировали музыкальные инструменты по двум основным критериям: источнику звука и способу извлечения звука. 
ных музыкантов XX в. Мунир Башир (1930-1997), египетский исполнитель на уде и композитор Рияд Аль-Сонбати (1906-1981) и др.

Другой музыкальный инструмент, который широко применяется на школьных уроках, это канун. Инструмент похож на инструмент «сантур» ${ }^{4}$, древний музыкальный инструмент, датируемый примерно пятью тысячелетиями. Канун в его нынешнем виде является арабским инструментом, относящимся к периоду Аббасидов, он был перенесен в Европу через Андалусию примерно в двенадцатом веке нашей эры.

Канун состоит из звуковой коробки, как правило, сделанной из орехового дерева на трапециевидной форме под углом, и имеет несколько отверстий под названием «солнце» для усиления звука. Канун обычно содержит 78 струн на каждые три струны одного звука и струны параллельной поверхности звукового блока. С левой стороны есть процедура натяжения струн, с правой стороны - так называема «лошадь», представляющая собой деревянную палочку с сухожилиями [4].

Канун считается одним из самых богатых музыкальных инструментов. Он состоит из трех с половиной октав и таким образом охватывает все музыкальные образы арабской музыки. По этой причине канун считается эталоном всех музыкальных инструментов и используется для того, чтобы адаптировать остальные музыкальные инструменты к настройке и балансировке своих инструментов. Канун является одним из главных музыкальных инструментов в ансамбле [5].

Исполнители на кануне: Мухаммад альАккад аль-Кабир (1850-1931), египетский исполнитель на кануне и композитор. Среди современников - сирийский музыкант Хасан Теннари и египтянин Маджед Сорур. Среди известных турецких музыкантов - Халил Кардуман, Хайх и Гюксель Пактагер.

К рассматриваемым нами национальным сирийским инструментам восходит най или трость, как некоторые любят его называть. Это музыкальный восточный инструмент, один из основных инструментов в арабской музыке. Использование его насчитывает более 4500-5000 лет.

Происхождение названия восходит к персидскому языку, что означает тростник, несмотря на множественность этого инструмента, но изначально это был полый тростник с открытым концом длиной около 45 см, диаметр которого постепенно уменьшается снизу вверх и имеет

${ }^{4}$ Сантур - традиционный иранский музыкальный инструмент. Он представляет собой подобие цимбал, причем корпус инструмента в форме трапеции изготавливают из ореха или различных экзотических пород дерева. шесть отверстий с одной прямой и седьмое отверстие посередине стебля с обратной стороны. Большие пальцы контролируют это. Изменились возможности и формы этого инструмента, а также его звуки и тона, так что най также стал металлическим [6].

Сначала най использовался в Месопотамии (Ирак), а фараоны использовали его на празднествах, чтобы быть ближе к богам.

Най приобрел большое значение в исламском мире после тринадцатого века и был тесно связан с суфизмом благодаря великому поэту и мудрецу Джалал ад-Дину Руми.

Семья най состоит из семи инструментов, которые различаются между собой тембрами, на которых они могут играть, так что каждый най соответствует высоте звука и своему собственному макаму.

А поскольку это восточный инструмент, он может издавать ноты в одном измерении, половинном измерении и трех четвертых с высокой точностью, что отличает арабскую музыкальную систему от западной. Но одного инструмента часто недостаточно, чтобы покрыть различную высоту звука музыкального произведения, поэтому мы часто слышим больше одного най.

Игра на най может показаться простой, но на самом деле для этого нужен определенный способ: удерживать най и дуть на него, чтобы контролировать звуки и мелодии, которые он производит. Самое важное правило игры на най - положить най сбоку ото рта, а затем продуть воздух под углом 45 градусов, чтобы удар на краю най, в зависимости от силы обдува воздуха, мог контролировать высоту тона най и определять тон.

Най в целом представляет собой простой инструмент с хорошо известной и типичной формой, но, несмотря на его простоту, существует несколько типов разной длины и несколько разный музыкальных эффектов, так как есть длинный най и короткий най, есть най для сольной игры и най для крупных концертов. Концертный най имеет слой, состоящий из трех октетов, и есть най с шестью отверстиями и най с семью отверстиями, потому что есть отверстие в середине язычка снизу. Существуют и другие типы най:

Най пикколо: най имеет высокий звук.

Альтовый най: этот най является самым громким из всех типов най, и он оснащен нижней четвертью концертной най.

Най бас: у этого типа довольно низкий звук, и он напоминает най пикколо для небольших концертов, но имеет восемь верхних.

Деревянный най: этот тип распространился в Египте, Древней Греции и Китае, а также в 


\section{Хасан Ахед}

Европе в середине восемнадцатого века нашей эры и в начале девятнадцатого века нашей эры [7].

Среди древних арабских музыкальных инструментах выделяется рабаба. Это древний арабский музыкальный инструмент с одной струной. Рабаба сделана из простых предметов, доступных кочевникам, таких как дерево, кожа козла или оленя. Рабаба также была одной из достопримечательностей андалузской музыки.

Музыкальный инструмент непохож ни на один другой, это один из старейших и самых известных инструментов, который до сих пор широко используется в сельской местности и на фестивалях наследия.

Источники приводят разные сведения по поводу происхождения рабабы: есть те, которые приписывают ее древним египтянам, другие считают, что ее происхождение - Месопотамия, где были обнаружены рисунки, относящиеся к шумерской эпохе. Существуют и те, которые полагают, что рабаба перебралась с Аравийского полуострова и распространилась на большие территории мира.

В каждой стране рабаба принимает особую форму. Рабаба на Аравийском полуострове не похожа на марокканскую, египетскую, индийскую, иракскую или турецкую, потому что форма этого инструмента отличается от страны к стране. Однако ее части, компоненты и размеры согласованы. Длина рабабы составляет 70 см, а ширина - от 25 до 30 см. Она принимает различные формы, включая круглые, прямоугольные и спиральные, а некоторые из них имеют несколько геометрических форм.

Рабаба состоит из частей, которые соединены между собой простым промышленным способом: корпус грифа, струн сделан из волос конского хвоста. В головку крепятся колки, для настройки инструмента, подставка, смычок, сделанный из мягкого бамбука [8].

Все инструменты, которые рассматриваются В этой статье, мы рекомендуем для применения в школьном образовании.

В заключение следует отметить, что большинство родителей хотят, чтобы дети научились играть на одном из этих инструментов, в первую очередь, чтобы сохранить музыкальное наследие, ведь в Сирии вряд ли найдется дом без народного инструмента. Кроме того, родители знают, какую большую роль играет музыка в формировании личности ребенка и какие возможности она дает для использования в будущем.

Поскольку в Сирии нет музыкальных школ, обучение игре на этих инструментах доступно для желающих и талантливых учеников в частных музыкальных клубах. В государственных школах учитель музыки отбирает талантливых учеников из каждого класса и работает над созданием специального школьного ансамбля. Репетиции проводятся по выходным, или можно выделить час после уроков два раза в неделю. В существующей педагогической нагрузке и школьном расписании на уроки музыки в младшей и средней школе отводится всего один академический час (45 мин.) в неделю, что явно недостаточно для серьезного и разнообразного музыкального образования. В большинстве школ отсутствуют музыкальные инструменты и технические средства, необходимые для проведения уроков музыки. Дети приносят с собой национальные музыкальные инструменты из дома, и преподаватели уделяют много времени для создания ансамблей, состоящих из арабских народных инструментов и ансамблевому музицированию.

\section{Список литературы}

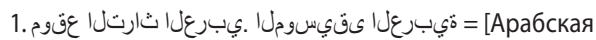
музыка // Арабское наследие: сайт]. URL: https://sites. google.com/site/toraatharabi/music (дата обращения: 23.05.2020).

بالط نم نيئدتب مل طبل طبسل

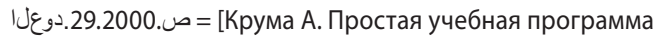
для начинающих учеников на уде. Тунис: Высш. ин-т музыки, 2000. 29 с.].

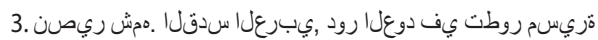

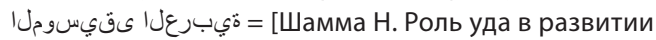
арабской музыки]. URL: https://www.alquds.co.uk (дата обращения: 15.06.2020).

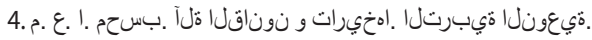
ץ.19. 9 ، 9 -^ = [Махмуд А. М. Канун и его история // Специальное образование. 2019. № 9. С. 9-10].

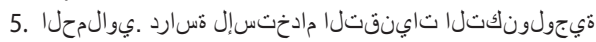

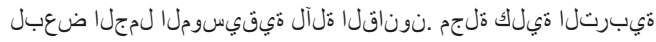

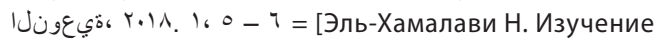
использования технических приемов для некоторых музыкальных предложений для инструмента канун // Журнал факультета специального образования. 2018. № 1. C. 5-6].

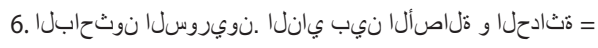
[Сирийские исследователи. Най между оригинальностью и современностью]. URL: https://www.syr-res.com/ article/10828.html (дата обращения: 10.08.2020).

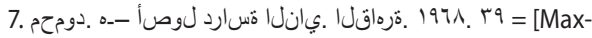
муд Е. Истоки изучения най. Каир, 1968. 39 с.].

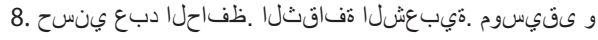
[Абдель Хафез Хосни. Народная культура. Музыкальное и динамичное исполнение] URL: https://www. folkculturebh.org/ar/?issue=38\&page=showarticle $\&$ id $=726$ (дата обращения: 20.08.2020). 


\section{Национальные арабские инструменты и их применение в музыкальной педагогике}

\section{References}

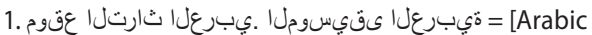
music. Arab heritage: website]. URL: https://sites.google.com/ site/toraatharabi/music (accessed: May 23.2020).

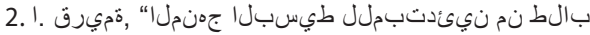
ب. beginners students in Ouda. Tunisia: Higher Inst. of Music, 2000. 29].

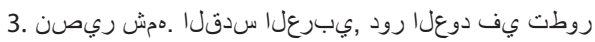
[Shamma N. Role of Ouda in the development of Arabic music]. URL: https://www.alquds.co.uk (accessed: June.15.2020).

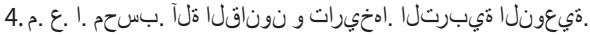
r.19. 9 ، $9-\wedge=$ [Mahmud A. M. Kanun and its history. Special education. 2019. 9, 9-10].
5. مجي جولونكتل

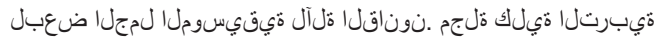

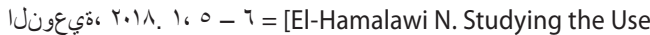
of Techniques for Some Musical Suggestions for the Eve Instrument. Journal of the Faculty of Special Education. 2018. 1, 5-6].

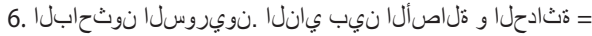
[Syrian researchers. Nai between originality and modernity]. URL: https://www.syr-res.com/article/10828.html (accessed: Aug 10.2020).

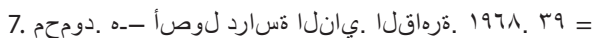
[Mahmoud E. The origins of the study of Nai. Cairo, 1968. 39].

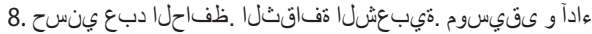
[Abdel Hafez Hosni. Folk culture. Musical and dynamic performance]. URL: https://www.folkculturebh.org/ar/?issu e=38\&page $=$ showarticle\&id=726 (accessed: Aug 20.2020). 